\title{
Intuição, pensamento e ação na clínica*
}

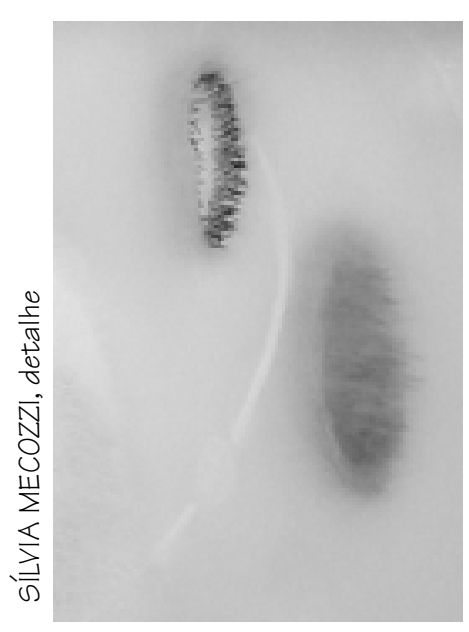

Maria Beatriz Lisboa Guimarães ${ }^{1}$

GUIMARÃES, M. B. L. Intuition, thought and action in the clinic. Interface - Comunic., Saúde, Educ., v.9, n.17, p.317-32, mar/ago 2005.

This is a theoretical-conceptual study, with two narrative axes: one in the field of philosophy and another one on the level of the sociological analysis of knowledge or culture, which, in this case, examines clinical discourse. This study intends to contribute to the analysis of diagnosis, therapeutics and care within contemporary western culture. The specific objective was to work with the category intuition as a basic element of knowledge within clinical practice, through the analysis of the process as it manifests itself among therapists and patients during treatment. We utilized the Intuitive Method proposed by Henri Bergson, aiming to discuss the limits of strictly rational thought and proposing the transposition of this method to the clinical sphere. In this study, intuition was treated as a synthetic form of perception/thought, in which the reality is apprehended by means of an immediate consciousness, guided by sensibility.

KEY-WORDS: intuition; health care professional-patient's relation; experience; clinical judgment.

O presente trabalho constitui um estudo de natureza teórico-conceitual, com dois eixos de narrativa: um no campo da filosofia, e outro no plano da análise da sociologia do conhecimento ou da cultura, que se deu, neste caso, na instância do discurso da clínica. Pretende-se contribuir para a análise da questão da diagnose, da terapêutica e do cuidado na cultura ocidental contemporânea. O objetivo específico foi trabalhar com a categoria da intuição como elemento básico do conhecimento da prática clínica, pela análise do processo que se manifesta em terapeutas e pacientes. Servimo-nos do Método Intuitivo proposto por Henri Bergson, visando colocar os limites de um pensamento estritamente racional e propondo a transposição deste método para a instância da clínica. A intuição foi tratada neste estudo como uma forma sintética de percepção/pensamento, na qual a realidade é apreendida por meio de uma consciência imediata, pautada na sensibilidade.

PALAVRAS-CHAVE: intuição; relação profissional-paciente; experiência; Julgamento clínico.

\footnotetext{
* Elaborado a partir de Tese de Doutorado (Guimarães, 2001).

${ }^{1}$ Pesquisadora visitante, Convênio Fundação Oswaldo Cruz/Fundação de Apoio à Pesquisa do Estado do Rio de Janeiro, RJ. <beatriz.guima@ensp.fiocruz.br>

Travessa Oriente, 65

Santa Teresa - Rio de Janeiro, RJ

20240-120
} 


\section{Introdução}

O presente texto dedica-se a abordar as relações existentes entre intuição $e$ prática clínica, trabalhando com o Método Intuitivo proposto pelo filósofo francês Henri Bergson (1859-1941), visando discutir os limites do pensamento estritamente racional e propondo a transposição desse método para a instância da prática clínica. Ele está sendo tratado como mais um instrumento a auxiliar o profissional de saúde, vindo a se somar a outros métodos utilizados nos processos de diagnose e terapêutica.

Iniciamos o questionamento sobre o tema da intuição a partir da constatação de uma certa insatisfação social em relação à racionalidade da medicina ocidental contemporânea $e$ ao atendimento disponível na sociedade atual. $O$ peso atribuído aos processos racionais do pensamento $e$ ao desenvolvimento tecnológico está levando uma parcela significativa da população a procurar formas alternativas de tratamento, em que uma visão mais integral do ser humano possa ser encontrada. O caminho que percorremos partiu, assim, da constatação da crise de valores sócio-culturais na racionalidade da medicina ocidental contemporânea, o que nos levou a procurar alternativas, em termos sócio-filosóficos, de procedimentos terapêuticos e, também, e isto é importante enfatizar, de mecanismos de apreensão do conhecimento.

Nesse sentido, a intuição pode ser um outro eixo de referência para pensarmos a crise da racionalidade médica ocidental, pois acreditamos que ela pode ocupar um espaço em nossa maneira de apreender a realidade e de buscar a cura para as doenças propriamente ditas, espaço até o momento negado no modelo dominante de percepção do adoecimento e da cura. Verificamos, como mostram pesquisas recentes na área, que desde o final da década de 1960, a crise do modelo médico ocidental começou a ficar mais evidente, uma vez que, em termos gerais, em seu aspecto cultural, não satisfaz parte crescente de sua clientela (Luz, 1997). Sabemos, entretanto, que esta crise não se configura como um bloco monolítico. É bem verdade que, para alguns setores da medicina ocidental, principalmente para a indústria farmacêutica, não se verifica crise alguma.

Partimos da análise do discurso da clínica que aborda o tema da intuição na prática terapêutica, utilizando artigos de periódicos das ciências médicas $e$ sociais encontrados em diferentes bases de dados ${ }^{2}$, para então abordar $o$ Método Intuitivo proposto pelo filósofo Henri Bergson. A construção do texto é feita aliando a análise do discurso da clínica, mediante depoimentos de terapeutas referentes a suas práticas, à perspectiva teórica sócio-filosófica, que procurou dar sustentação e legitimidade a esses discursos. Foram encontradas referências bibliográficas sobre intuição nas áreas de enfermagem, medicina e áreas denominadas por nós de "psi" - psicologia, psicanálise e psiquiatria.

É interessante e significativo observar que a maior parte dos artigos que abordam a intuição na clínica situa-se no campo da enfermagem. Isto pode ser explicado pelo fato de que atualmente o cuidado com os pacientes se encontra nas mãos dos enfermeiros, uma vez que eles estão mais em contato com o doente, tendo a tarefa de cuidar de sua saúde e assistir o doente. Outro fator que chama atenção é a predominância de autoras (sexo
${ }^{2}$ As bases utilizadas foram a Medline,

Bireme, Lilacs, Cochrane Library, Embase, Current Contents e Best Evidence. Não foram obtidas referências bibliográficas nas bases de dados tais como: Cochrane Library, Embase e Best Evidence. 
${ }^{3}$ Adotamos a definição de espírito baseado em dois filósofos da imanência, a saber: Bergson, na qual o espírito ou alma é constituído de uma substância não-física que não podemos ver $e$ tocar, isto é, os sentimentos e os pensamentos, $e$ associa o espírito ao próprio tempo, ou seja, à duração interior de cada corpo, que perpassa todos os indivíduos, sendo caracterizado como aquilo que anima e dá vida aos seres, isto é, o elã vital; $e$ Espinosa, em que o espírito ou alma não constitui uma entidade separada do corpo, mas é a expressão de tudo que se passa na corporeidade, ou seja, tudo aquilo que afeta o corpo, $e$ lhe aumenta ou diminui a potência. A alma, para Espinosa, é a idéia do corpo, no sentido de que ela é capaz de perceber as idéias das modificações (afecções) do corpo.

Enquanto a essência do corpo é a potência para existir e agir, a da alma é para pensar. Estes autores associam a alma à mente, $e$ afirmam que corpo, mente e cérebro são manifestações inseparáveis de um organismo vivo. feminino) que se interessam por este tema, o que pode estar relacionado ao fato de que a enfermagem é uma prática terapêutica exercida tradicionalmente pelas mulheres. Mas podemos indagar também se o tema da intuição não teria mais afinidade com o "feminino", uma vez que na nossa sociedade a relação entre o cuidado e o gênero feminino foi sendo construída ao longo dos séculos.

\section{As múltiplas "visões" da intuição}

Segundo a etimologia do termo, intuição vem da palavra latina intuitus: "in"- em, dentro, e "tuitus", particípio passado de "tueri" - olhar, ou seja, "olhar dentro" (Muniz, 1988). Visão voltada para dentro de si ou ainda olhar a partir de dentro de si.

A intuição sempre esteve presente nos sistemas filosóficos desde a Antigüidade grega até a filosofia contemporânea, tendo sido apresentada com diversos sentidos. O que todos têm em comum é a compreensão da intuição como visão imediata (sem mediação) de algo na sua totalidade. No dicionário de filosofia de Brugger (1977), intuição é a visão direta de algo existente, que se mostra imediatamente em sua concreta plenitude (isto é, sem intervenção de outros conteúdos cognitivos), em outras palavras, é o conhecimento que apreende o objeto em seu próprio ser presente. Em sentido similar, o dicionário de filosofia Lalande (1993) define intuição como sendo a visão direta $e$ imediata de um objeto de pensamento atualmente presente no espírito e apreendido em sua realidade individual.

Bergson (1974) inova em relação às concepções tradicionais quando coloca o espírito ${ }^{3}$ como objeto da intuição, apreendido imediatamente como realidade temporal. Visão direta do espírito pelo espírito, consciência alargada, percepção imediata, experiência espiritual ampliada são todas referências à intuição (Maciel Jr., 1997). Bergson ressalta, contudo, a dificuldade em defini-la, pois a intuição supõe sempre o tempo ou a duração $e$, por conseguinte, o movimento: o prolongamento ininterrupto do passado num presente que penetra no futuro. Ao longo do artigo explicitaremos melhor esse ponto.

Em seguida, apresentamos diferentes definições para a categoria da intuição encontradas nos artigos de enfermagem, medicina e áreas "psi". No artigo de Tatano Beck (1998), a intuição é definida como um conhecimento obtido de uma maneira imediata e percebido como uma totalidade; um processo linear de raciocínio não é usado para alcançar este tipo de conhecimento. $\mathrm{O}$ autor afirma que intuição não é um sexto sentido mágico, mas um tipo de raciocínio sofisticado, baseado na organização de informações dentro de padrões, e que ultrapassa a separação dos passos analíticos. Acrescenta que essa habilidade de recolher informações desenvolve-se a partir da experiência.

King E Appleton (1997) também sugerem que a percepção intuitiva na prática da enfermagem é a habilidade de, numa situação clínica, reunir elementos em uma totalidade, que originalmente se encontravam dispersos. Para as autoras, os atributos da intuição na enfermagem podem ser definidos como a integração de formas de conhecimento que se dão numa realização repentina. 
No mesmo artigo, as autoras identificam o que foi chamado de 'gestalt da enfermagem', a matriz na qual os enfermeiros unem conhecimentos, experiências passadas, exemplos de casos clínicos e descarga de sentimentos (King \& Appleton, 1997).

No artigo de English (1993), a intuição é relacionada à capacidade de o profissional de saúde identificar crises potenciais nos pacientes, antes que mudanças clínicas significativas tornem-se evidentes. E afirma que a percepção sensível é central para o bom julgamento da enfermagem, $e$ isto começa com um pressentimento vago e uma avaliação global que inicialmente passa por uma análise crítica. Freqüentemente, enfermeiros experientes descrevem suas habilidades perceptivas usando expressões como: descarga de sentimentos, uma sensação de inquietação ou o sentimento de que algo não vai bem.

No artigo de King \& Appleton (1997), as autoras atestam que o reconhecimento do uso da intuição na prática clínica da enfermagem tem crescido proeminentemente nos últimos vinte anos. Entretanto, esse reconhecimento ainda não é consensual, pois de acordo com Benner \& Tanner (1987), apesar de considerarem a intuição um aspecto legítimo e essencial do julgamento clínico, alertam para o fato de que ela tem sido vista como baseada em atos irracionais, advinda de um conhecimento infundado ou mesmo de inspiração sobrenatural, e admitem existir uma certa relutância para conceder legitimidade à abordagem intuitiva no ato de fazer um julgamento clínico, sugerindo que esta intolerância está subjacente à cultura ocidental que demanda uma explicação racional do mundo. Contudo, as autoras chamam atenção para a importância da experiência no bom desempenho da prática clínica, pois, por meio da qual os profissionais aprendem a utilizar suas percepções de modo que podem levar a confirmar evidências. Afirmam, ainda, que a intuição, definida como 'entendimento sem o racional', poderia ser caracterizada como uma arte mais do que como uma ciência e, assim sendo, é única, criativa e não pode ser mensurada nem submetida a uma verificação objetiva nos mesmos moldes aplicados à ciência.

Sem dúvida, podemos constatar que uma certa aura de mistério ronda a questão da intuição, por ela fazer parte de algo que foge à nossa compreensão racional, entretanto, não queremos associá-la a esferas sobrenaturais, pois é no seio da própria imanência ou da dimensão espiritual do ser que ela se realiza. É interessante ressaltar que, apesar de os sentidos atribuídos à intuição variarem de um autor para outro, todos concordam que é uma forma de apreensão do conhecimento que se dá de uma maneira sintética, imediata e inexplicável, ancorada na experiência, indicando algo da esfera do sensível, peculiar apenas para aquele que sente, e que resulta na criação de algo novo.

\section{Experiência e intuição}

Conforme pontuamos acima, parece ser consensual entre os profissionais de saúde a afirmação de que a experiência é considerada um componente necessário da intuição. Nesse sentido, Easen \& Wilcockson (1996) assinalam que o sentido é produzido na experiência, e que experiência sem intuição consistiria em uma série de simples eventos na qual faltaria direção ou significado. Como sugerido no artigo de O’Connell (1992), um enfermeiro é considerado expert por possuir conhecimento e experiência acumulada, pois 
somente com isso ele poderá ter uma compreensão adequada da prática da enfermagem.

A experiência com os casos clínicos auxilia muito este tipo de conhecimento. O olhar, a escuta e o toque de um profissional de saúde experiente e envolvido com os problemas trazidos por seus pacientes são fundamentais para o bom julgamento clínico. Com a experiência, o profissional de saúde sabe distinguir um caso grave de uma cena corriqueira. Desse modo, vemos que a intuição tem pelo menos duas pernas, uma que está ancorada no conhecimento anterior ou já dado, e outra que advém no momento presente em que está se dando. Sendo assim, por mais que apostemos no valor do acontecimento e do devir, não deixamos de acentuar o valor da memória e do conhecimento acumulado. Neste sentido, é bom frisar que a intuição não surge do nada, é necessário que o indivíduo esteja preparado para poder receber este novo conhecimento que emergirá.

$\mathrm{O}$ acontecimento proporciona ao ser humano a vivência de microssensações e micropercepções que vão afetando o corpo de diferentes maneiras, ao passo que as idéias produzidas vão sendo armazenadas na memória. Com o tempo, os interesses práticos do dia-a-dia vão recobrindo essas lembranças, deixando-as em estados inconscientes. Mas quando algo estranho ou não reconhecido ocorre, a sensibilidade logo procura resposta que dê sentido àquele acontecimento. Alguns enfermeiros dizem acontecer o seguinte: "Você vê muita coisa e alguma coisa faz você lembrar o que viu e procura por isto de novo. Eu não sei se você procura por isto conscientemente, mas você se lembra (...) Eu acho que você desenvolve isto com a experiência". Ou ainda, nas palavras de outro enfermeiro: "Você experimenta algo e aquilo fica ali na sua mente, mas você não sabe o que é, não obstante ele está lá - algo.” (Cioffi, 1997, p.204).

As descrições desses dois enfermeiros sugerem um conhecimento sutil operando sob a consciência que nasce da experiência e fica na memória à disposição para ser chamado em situações clínicas apropriadas. Esta noção da intuição é individual. O que é intuitivo para uma pessoa pode não ser para outra. Esses julgamentos intuitivos são apresentados como subjacentes aos processos conscientes e não são suscetíveis de serem explicados de uma maneira tangível (Cioffi, 1997).

Nesse sentido, a intuição é especialmente necessária diante de acontecimentos inesperados e não imediatamente reconhecidos pelo profissional de saúde. English (1993) propôs que eventos atípicos e inesperados que não se conformam com as expectativas deveriam receber atenção redobrada. Pois quando uma cena comum é vista, um plano de ação apropriado é ativado e uma representação é formada. A atenção é maior quando ocorre algo inesperado. Esta acuidade perceptiva se desenvolve apenas depois de muita experiência em situações similares.

O que os enfermeiros dizem ocorrer é que, com a experiência ou por meio de um conhecimento tácito, complexas seqüências de ações podem se tornar tão rotineiras pela prática e experiência, que são executadas semiautomaticamente. Em outras palavras, a consciência associada a essas ações profissionais freqüentes e repetitivas tende a retroceder, enquanto a atenção na percepção de aspectos pouco usuais da situação aumenta (Easen \& 
Wilcockson, 1996). Eles fazem referência a esse tipo de conhecimento como baseado numa inteligência do corpo e citam como exemplo a situação de quando um enfermeiro experiente precisa pegar uma veia, ele prova que o cateter é quase uma extensão dos seus dedos e não um objeto estranho. Isto possibilita ao profissional de saúde deixar sua mente livre para perceber outras manifestações do acontecimento.

É interessante observar, conforme Thomas Kuhn pontuou, que é justamente o reconhecimento de anomalias, discrepâncias e exceções que freqüentemente levam ao descobrimento de uma verdade. Mas para tanto é necessário uma mente aberta, receptível e disponível para estas possibilidades; isto foi percebido astutamente por Louis Pasteur, ao afirmar que: "no campo da observação, o acaso favorece a mente preparada" (Meyers, 1995).

O filósofo contemporâneo Gilles Deleuze propôs uma teoria acerca de como um novo pensamento é acessado em nossas mentes, contrário ao que fora proposto por Platão, mas que se assemelha a nossa abordagem. O pensar, para a filosofia de Deleuze (1988), não é reconhecer algo que já se encontrava em outro mundo, tal como concebido por Platão, mas sim problematizar, ou seja, colocar uma nova idéia. Pensar é o que advém da falência dos hábitos, não é natural; para nascer precisa sempre de uma ocasião fortuita ou da contingência de um encontro. É necessário que algo violente o pensamento já estruturado, uma estranheza ou uma inimizade para tirá-lo de seu estado natural. É justamente quando não reconhecemos o que vemos de uma forma adequada à nossa visão anterior que somos forçados a pensar ou, porque não dizer, a criar. Pois quando não reconhecemos ou quando não conseguimos ter clareza para agir em uma determinada situação, de imediato um estranhamento se impõe. Neste momento, nosso conhecimento intelectual/racional anterior se dissipa por não sabermos utilizá-lo na nossa vida prática, por não sabermos, portanto, nos servir dele. Isto coloca uma questão que nos força a pensar. Neste sentido, o pensar só advém ao pensamento quando somos forçados. E nesta instância, somente a sensibilidade poderá suscitar uma resposta ao problema, trazendo-a sob a forma de uma nova idéia ou uma nova criação, pois somente a sensibilidade é capaz de juntar os pensamentos que se encontram dispersos e fazer a síntese sob a forma de um novo pensamento.

Um profissional de saúde experiente ou atento aos sinais que o paciente emite é capaz de reconhecer quando algo não vai bem. E são justamente nas situações mais atípicas, quando o profissional de saúde não reconhece os sintomas que o paciente está emitindo, isto é, quando os sintomas não se enquadram no diagnóstico anterior, que uma atenção redobrada é requerida, fazendo com que o profissional se coloque por inteiro na relação para que ele possa captar pequenas pistas, indícios ou sinais que estão permeando a situação. É necessário que o sujeito que observa saiba captar aquele sinal, relacionando-o com outros sinais que possam se traduzir num diagnóstico ou numa terapêutica. Daí a importância da experiência acumulada e do conhecimento prévio.

Canguilhem (1997) também assinala o valor da experiência nas questões referentes à saúde, quando afirma que as categorias de saúde e doença só são reconhecidas no plano da experiência (e não no plano da ciência), pois, segundo o autor, "a vida não é, para o ser vivo, uma dedução monótona, um 
movimento retilíneo; ela ignora a rigidez geométrica, ela é debate ou explicação com um meio em que há fugas, vazios, esquivamentos e resistências inesperadas" (Canguilhem, 1978, p.160). Ou seja, a vida foge ao esquadrinhamento e à formatação que as ciências pretendem impor, pois sua expressão vivenciada pelos seres humanos se faz a cada momento, trazendo sempre uma ou muitas novidades. Como Martins (1999) bem argumentou, em termos éticos, as ciências da vida ganharão quando compreenderem a vida não mais como um objeto a ser dominado, justamente pelo medo de ver a vida como devir, movimento, pulsão, inesperado.

Queremos agenciar intuição com experimentação para que possamos pensáça ocorrendo a partir da vivência compartilhada entre terapeuta e paciente, em tudo aquilo que se passa entre esses atores sociais. Ou seja, tomar a prática de operar com e não sobre o paciente; e o que isto quer dizer? É a participação ou o engajamento do profissional de saúde no processo de cura do sujeito doente, compartilhando com ele sensações, histórias, transformações, em vez de se colocar na posição de detentor do saber que se instaura de maneira fria $e$ distanciada por sobre os pacientes.

Silva (1993), em depoimento sobre sua prática de enfermagem em um hospital de pacientes com AIDS, refere-se ao desejo que sente de não impor um modelo de ação no seu atendimento clínico, mas, ao contrário, deixar-se guiar pelas necessidades que são impostas nas situações do momento. Ao dirigir-se para o encontro com os clientes, a enfermeira relata que apesar de possuir a predisposição de fazer o melhor, nunca sabe ao certo o que irá acontecer, tendo em vista a participação dos clientes neste processo.

Silva observa que as intuições fluem com maior intensidade à medida que sua capacidade de sintonização e receptividade é mais acentuada. Entretanto, enfatiza que é muito difícil explicar o processo intuitivo, mas sabe que consiste em um dos requisitos básicos para o efetivo processo de cuidar. Concluindo, constata que quando utiliza o dispositivo da intuição, suas ações fluem com espontaneidade, transformando seu atendimento em momento rico de aprendizagem e de novas experiências e, ao mesmo tempo, agradável. Em sua prática profissional anterior, detectava que existia a angústia e preocupação em cumprir a cada dia os objetivos traçados, levando, conseqüentemente, a uma prática impositiva, improdutiva e cansativa.

Caminhando nessa mesma direção, Easen \& Wilcockson (1996) descrevem a maestria artística do profissional experiente como o processo no qual o insight na situação presente não precede a ação, mas emerge no curso dela. Esta perspectiva que privilegia os acontecimentos significativos que ocorrem no curso do tempo é uma importante questão que merece ser tratada com empenho. Pode-se dizer que ela constitui uma das questões que fundamentam e dão sustentação a este trabalho. Iremos relacioná-la ao conceito de duração em Bergson.

\section{O conceito de duração e o método intuitivo de Bergson}

Bergson (1974) afirma existirem duas formas de conhecimento, colocadas lado a lado, constituindo duas direções divergentes da atividade do pensamento: uma que é obtida pela inteligência e outra, pela intuição. A primeira visa inserir o ser humano no mundo material de forma eficaz; sua função básica consiste 
em presidir ações. Para Bergson, toda nossa existência visa basicamente à satisfação de nossas necessidades e interesses práticos.

A inteligência, quando destinada à satisfação de interesses materiais, isto é, aplicada ao terreno prático, é eficaz; o problema se coloca quando ela se propõe a dar a chave do conhecimento do real tal como ele é em si. Pois, para Bergson, a realidade se apresenta como um processo contínuo de fluxo e transformação, $e$ a inteligência, ao fixar o real em representações esquemáticas, enquadrandoas em categorias fixas e imutáveis, perde o movimento que o caracteriza. O erro da inteligência é pensar que o real já está dado. Ao contrário, ele devém a cada momento, e o faz diferenciando-se. Nesta instância, a inteligência engendra ilusões causadas por se generalizar idéias que só se aplicam ao terreno prático e circunstancial.

A mais flagrante de todas as ilusões consiste, segundo Bergson, em crer que podemos pensar no instável por meio do estável, no movente por meio do imóvel, ou seja, a inteligência é incapaz de compreender a essência da natureza do espírito, uma vez que esta essência consiste em fluir, ao passo que a inteligência só retém do real momentos fixos e descontínuos, levando-nos, com isso, a uma compreensão inadequada da realidade.

Neste sentido, a inteligência, atenta à exatidão e à abstração, destaca do devir determinados momentos significativos, transporta-os para um espaço auxiliar e os analisa decompondo-os em uma série de instantes descontínuos, como algo já feito, ignorando o processo em que eles se fazem (Maciel Jr., 1997). A duração real é assim sistematicamente desviada. Para Bergson, "a essência da duração está em fluir. O real não são os 'estados', simples instantâneos tomados por nós ao longo da mudança; é, ao contrário, o fluxo, é a continuidade de transição, é a mudança ela mesma." (Bergson, 1974, p.110).

O devir é o processo de transformação de algo em outro, a metamorfose ou o tornar-se. Sua consistência é a própria transformação: é o que Bergson denomina de duração, ou seja, aquilo que está se dando, que é a própria passagem do tempo ou o desenrolar do tempo, e que consiste em um fluxo de criação no qual cada momento é inteiramente novo.

Com o intuito de reprimir as ilusões da inteligência, Bergson propõe, então, uma apreensão imediata da realidade, que só se viabiliza por meio da intuição. Explorando a categoria da intuição, o autor elabora seu método filosófico.

A compreensão da duração é importante para o método intuitivo, pois a intuição supõe a duração, ou seja, a intuição consiste pensar em termos de duração. A intuição é o movimento pelo qual saímos de nossa própria duração, ou nos servimos de nossa duração para afirmar e reconhecer imediatamente a existência de outras durações diferentes em natureza da nossa (Deleuze, 1987). Podemos perceber tantas durações quantas queiramos, todas diferentes entre si, mas o que todas têm em comum é o fato de estarem compartilhando um mesmo momento no tempo, pois para Bergson existe um só tempo, denominado de "Todo", ainda que haja uma infinidade de fluxos.

Bergson alia duração à subjetividade, isto é, para ele, a subjetividade é interior ao tempo. Vivenciar a experiência do tempo ou da duração é estar presente no aqui e agora, mergulhando no interior do momento; é apreender a 
emergência de algo, nele se fazendo. Neste sentido sujeito e objeto não são prédeterminados, são construídos na medida em que o tempo passa, e são ressignificados a cada momento. A vida, dessa forma, passa a ser produção, criação de diferenças. Somente nesta experiência do tempo ocorre o novo, advém a criação; tudo mais são representações, são elementos já conhecidos. $O$ que nos distancia de estarmos sempre presentes no aqui e agora são nossos interesses práticos, pois, para darmos conta deles, alienamo-nos de nossos impulsos criativos. Portanto, para se conhecer o todo, não é preciso sair de si mesmo, pelo contrário, tem-se que voltar para dentro de si para poder apreender o todo que coexiste com o momento presente.

Neste sentido, para que a intuição possa emergir, é necessário desinteressarse da vida prática e saber ver a passagem do tempo em seu duplo jogo simétrico, ou seja, estar presente no aqui e agora, sentindo a passagem do tempo. E, para que isso possa se dar é necessário, de acordo com Bergson, esvaziar a mente ou deixá-la livre de representações, com apenas os sentidos presentes na duração do tempo e ao que acontece a sua volta, para que a sensibilidade possa apreender aquele momento em sua totalidade. Vivenciar a duração bergsoniana e ser capaz de criar e intuir algo novo implica um certo desprendimento do ego ou do self, para poder situar-se na duração e estar presente no acontecimento e não no próprio umbigo, amarrado a sua teia de significados.

A intuição ocorre quando o pensamento racional - nos moldes da inteligência prática/interesseira - é submetido à crítica, permitindo que a atenção se volte para o espírito ou para a sensibilidade. Neste momento, o sujeito vive a duração presente; e, num lapso de tempo, por meio de uma consciência imediata pautada nos sentidos e na sensibilidade, sobrevém um problema ou uma nova idéia. Para Bergson, colocar o problema é mais crucial do que resolvê-lo, pois implica uma invenção, ao passo que a resolução advém, cedo ou tarde. Assim como o domínio da inteligência é a matéria, para Bergson o domínio da intuição é o espírito. E sugere que existe algo de divino no espírito que se insere como criador de novas idéias, fruto do pensamento intuitivo, porque, para ele, somente esse conhecimento é realmente criador, no sentido de trazer algo novo, pois somente o pensamento intuitivo consegue captar o momento presente em todas as instâncias que o compõem denominado por Bergson de "Todo". Isto é, consegue sintetizar ou elaborar conscientemente as diferentes idéias e sentimentos dos diferentes fluxos $e$ durações presentes numa dada situação (a totalidade para Bergson não é prédeterminada, mas é uma totalidade aberta e em processo). O pensamento intelectual, por outro lado, re-elabora idéias já preconcebidas.

A intuição apresenta-se sempre como uma totalidade, sob a forma de síntese, mas logo em seguida vem o pensamento racional para elaborar, comparar e analisar aquilo que foi intuído, recorrendo ao conhecimento que o sujeito já possuía anteriormente: nisto consiste o Método Intuitivo proposto pelo autor. Essas duas formas de pensamento não são, portanto, excludentes, mas sim complementares. Convém esclarecer que não estamos opondo razão à intuição, a razão está presente tanto no pensamento intelectual quanto no intuitivo, só que no primeiro caso ela está pautada em idéias previamente concebidas e no segundo, a razão está a serviço da intuição. 
A intuição é, neste sentido, a capacidade de o espírito captar, sem mediação da razão e de uma maneira sintética, aquilo que foi apreendido pelo corpo. Esta reação do espírito pode ser percebida por meio de uma forte emoção que o arrebata. Essa emoção, que Bergson denominou de criadora, é caracterizada por um estremecimento afetivo da alma, advindo da sintonia com a duração do todo, que se expressa na criação de algo novo. É como se o impulso vital se auto-afetasse (Maciel Jr., 1997). Nesse estado, os processos conscientes de pensamento dão vazão aos sentimentos, permitindo que a intuição funcione como um gatilho para impulsionar e trazer à tona os estados inconscientes do ser, por meio de um processo associativo. Desse modo, o espírito é capaz de captar uma realidade mais profunda, de outra forma inatingível. Por sua vivência, a intuição auxilia o sujeito a distinguir o essencial do não essencial. A intuição é a própria criatividade expressando-se na vida, por isso o restabelecimento da saúde dá-se por meio da criação de novas formas de vida, como ressaltou Canguilhem (1978), por vezes superiores às antigas.

Convém esclarecer que o terapeuta/profissional de saúde não faz o diagnóstico com base em uma "inspiração divina”. É essencial a formação e o conhecimento construído e acumulado durante todos os anos de aprendizagem e exercido na prática clínica do profissional para que ele tenha condições de fazer diagnósticos e estabelecer terapias. O método intuitivo de Bergson está sendo proposto para ser aplicado na instância da clínica como mais um instrumento a auxiliar este profissional no seu trabalho cotidiano. A intuição se dá a partir dos sentidos e da sensibilidade que se expressam quando o sujeito está em sintonia com o momento presente, pulsando junto com o outro e com o "Todo", e atento aos sinais e sintomas trazidos por seu paciente/cliente. É bom enfatizar que a intuição necessita do pensamento racional para elaborar, discernir e avaliar aquilo que foi intuído no corpo pelos sentidos, e também da instância de elaboração racional que foi construída anteriormente à captação intuitiva pelo profissional de saúde e que se encontra armazenada em sua memória.

O julgamento intuitivo é uma maneira de sentir/julgar própria de cada pessoa, como já foi dito anteriormente, mas que não se dá a partir de um nada e sim a partir de uma mente preparada e em sintonia com a situação do momento que envolve o outro, a percepção de si mesmo (percepção duplicada, em que o sujeito se vê vendo na situação presente) e de tudo aquilo que os circundam. A intuição não emerge de uma postura centrada no ego, mas, ao contrário, de uma atenção voltada para o momento presente, diluída no "Todo" bergsoniano.

\section{Aspectos que descrevem o pensamento intuitivo}

Iremos agora nos deter em explorar uma pesquisa realizada na Escola de Enfermagem da Universidade de Connecticut, USA, em que o professor Cheryl Tatano Beck (1998) solicitou a vinte e um enfermeiros que descrevessem uma experiência em que tivessem feito uso da intuição em sua prática clínica. Como resultado, as seguintes características do pensamento intuitivo foram identificadas:

- uma descarga de emoções arrebata os enfermeiros quando eles percebem que algo não vai bem; 
- ouvir sua própria intuição envolve um compromisso consciente em acompanhar persistentemente o estado de seu paciente;

- intuição envolve observação astuta de insinuações sutis não-verbais $e$ mudanças no comportamento normal do paciente.

Vamos nos deter um pouco em cada um desses itens. O primeiro ponto relaciona a intuição a uma descarga de emoções. Como já foi abordado anteriormente, para Bergson (1974), a intuição provém dos sentidos e da sensibilidade e é obtida por meio de um tipo de emoção que se manifesta de modo arrebatador, num lapso de tempo, sob a forma de uma descarga. Este tipo de emoção não é suave nem está condicionada por hábitos e obrigações, pelo contrário, é vivenciada como um arrebatamento do espírito, conferindo um certo grau de certeza com relação àquilo que foi intuído. Essas emoções simplesmente chegam à mente de quem intui sem que se saiba o modo ou os degraus percorridos. Em muitos casos, essa descarga de emoções é associada a sensações físicas que podem se expressar por sintomas, como por exemplo, pele ruborizada, boca seca, tensão muscular e pulso acelerado (King \& Appleton, 1997).

E é justamente pelo fato de o profissional de saúde não saber identificar com precisão o modo como o pensamento intuitivo chega a sua mente, que esse tipo de pensamento ou julgamento é, em muitos casos, menosprezado pela comunidade médica. Segundo Benner \& Tanner (1987), a maior parte dos insights e julgamentos significativos podem ser descartados ou desacreditados, em virtude de sua aparente falta de evidência concreta. O profissional fica com um sentimento de desvantagem por não possuir um conhecimento legitimado, mesmo estando certo de seu julgamento clínico.

O segundo ponto refere-se à necessidade de o profissional de saúde acompanhar de perto o estado de saúde de seu paciente. King \& Appleton (1997) também reconhecem a importância dessa atitude e afirmam que conhecer o paciente ou cliente e envolver-se com seu cuidado são elementoschave que fortalecem a intuição dos profissionais.

Este ponto pode ser desdobrado em pelo menos dois aspectos que, de uma certa maneira, se complementam. O primeiro diz respeito ao cuidado e o segundo ao envolvimento emocional. Benner, ao comentar o artigo de Orlick (Orlick \& Benner, 1988), acentua o papel fundamental que o cuidado desempenha na reintegração do indivíduo à sociedade $e$ na sua conseqüente recuperação. Segundo a autora, o cuidado reintegra o indivíduo doente ao seu mundo e constitui um ingrediente essencial para sua recuperação, pois os pacientes não são persuadidos a retornar a um mundo que é frio, impessoal $e$ técnico, pelo contrário, eles são persuadidos pelo cuidado e freqüentemente esse cuidado precisa ser expresso de maneira individualizante, que fuja da convenção e da rotina hospitalar. A autora conclui afirmando que enfermagem é mais do que mera técnica.

A palavra cuidado, de acordo com Boff (1999), deriva do latim cura, usada em um contexto de relações de amor e amizade. Outros derivam cuidado de cogitare-cogitatus, tendo o mesmo sentido de cura: cogitar, pensar, colocar atenção, mostrar interesse, revelar uma atitude de desvelo e de preocupação. $\mathrm{O}$ cuidado faz parte da essência humana e não é apenas um ato pontual, mas sim a forma como a pessoa humana se estrutura e se realiza no mundo com os 
outros (Boff, 1999). Requer uma atitude de envolvimento, de preocupação e de responsabilização para com o próximo, pois compreende o acolhimento, a escuta do sujeito, o respeito por seu sofrimento e por sua história de vida. A relação não é de domínio sobre, mas de con-vivência, e sua centralidade não é ocupada pelo logos - razão, mas pelo pathos - sentimento.

Por outro lado, Illich (1975), ao abordar a questão do cuidado, faz uma crítica ao cuidado heterônomo, expropriador da saúde dos indivíduos, presente na medicina atual, isto é, um cuidado que vem sob a forma de prescrições médicas, exterior ao indivíduo e imposto a ele de forma coercitiva. $\mathrm{O}$ autor associa saúde ao grau de liberdade de lutar e de se auto-afirmar que um indivíduo possui. Nesse sentido, entende que a medicina atual, pautada no desenvolvimento tecnológico, expropriou a saúde dos indivíduos, na medida em que delegou para si o saber referente ao cuidado com a saúde, desqualificando as práticas tradicionais e/ou alternativas, e deixando o homem moderno despreparado para lidar com o adoecimento, o sofrimento e a morte. Acresce-se a isto o fato de que, em geral, na medicina dominante em nossa sociedade, especialmente no atendimento público de saúde, os sujeitos são vistos como portadores de doenças, não sendo tratados de modo integral $e$ nem valorizados em sua humanidade e individualidade. Outro fator agravante nesse sentido é o fato de que a medicina privilegia os aspectos físicos/biológicos da doença em detrimento dos fatores subjetivos que influenciam no adoecimento dos sujeitos, esfera restrita aos atendimentos psicológicos.

A questão do cuidado remete a um outro ponto que se relaciona ao envolvimento emocional do profissional de saúde com o paciente. De início, acreditamos que sem envolvimento não há cuidado, no sentido integral do termo, pois sem uma atitude de desvelo e de atenção para com o outro, a intenção de cura não se apresenta $e$, portanto, não se efetiva. O trabalho mecânico e técnico do profissional de saúde, mesmo que tenha o objetivo de cuidar do paciente, pode salvar vidas, mas não consegue atingir o sentimento $e$ o sofrimento de quem adoece (Tesser, 1999).

No artigo de Easen \& Wilcockson (1996) os autores afirmam que a interação entre estados emocionais e processos cognitivos é crucial para o processo da intuição, e que as percepções associam-se a emoções. Relatos de diferentes médicos e enfermeiros ressaltam o valor positivo do envolvimento emocional com o paciente. Eles dizem ter vivido uma certa incongruência entre o que haviam aprendido nas escolas ou faculdades e o que experimentavam no cotidiano com os pacientes. Nas escolas, ensinavam que não deveriam envolverse emocionalmente com os indivíduos doentes e que deveriam manter uma certa distância e frieza técnica a fim de preservar o bom trabalho clínico $e$ alcançar melhores resultados no tratamento. Na prática, especialmente nos hospitais, muitos profissionais de saúde demonstraram satisfação ao tratarem seus pacientes de uma forma humana, calorosa e atenciosa, pois desse modo os pacientes reagiam melhor ao tratamento e os profissionais sentiam-se mais seguros.

Com base no Método Intuitivo proposto por Bergson e aplicado à instância da prática terapêutica, para que a intuição possa emergir é necessário que tanto terapeuta quanto paciente se envolvam por completo na relação que se instaura no momento da consulta e/ou atendimento. O que chamaremos de

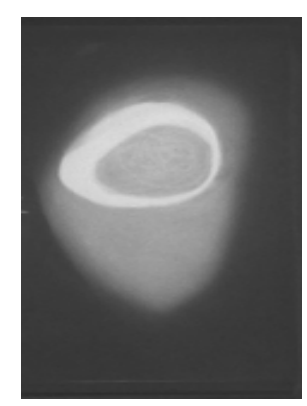


envolvimento por completo é a presença, em especial do profissional de saúde, com todo o seu ser, incluindo seu corpo e seu espírito, em tudo que diz respeito ao seu paciente: seus gestos, olhares, palavras, silêncio. É necessário que haja um caminho de ida e volta entre o paciente e o profissional de saúde, de modo que a percepção se duplique e o espírito se veja presente na situação do momento. Ou seja, ao mesmo tempo em que o profissional de saúde está com sua atenção voltada para o paciente, ele também se volta para si mesmo, tendo consciência do seu ser presente naquele momento. Isto requer uma atenção rigorosa, isto é, uma consciência de si, do outro e da interação que está se dando entre ambos. Requer também que a mente não esteja ocupada com lembranças ou antecipações que não fazem parte do universo presente naquela situação. Esta visão retoma o viver o aqui e o agora preconizado pelos Pré-Socráticos e também pelos Budistas. É necessário, portanto, um certo "quietismo de sentir", um certo "vazio", ou ainda um desprendimento do ego, para que só o espírito ou a sensibilidade possa viver neste fluxo. Assim, o tempo, o processo e o co-funcionamento são cruciais para que a consciência possa se desprender dos interesses práticos e de modelos predefinidos, para entrar no próprio fluxo do tempo, que Bergson denomina de duração, no qual estão presentes os sinais capazes de dar as chaves para os caminhos da cura.

Um ponto explorado por diferentes autores refere-se à relação entre o processo intuitivo e a receptividade do profissional de saúde e do paciente ao tratamento. Eles consideram que o "estar aberto" para receber novas informações ou idéias e para lidar com dados incompletos e pouco claros são atributos que facilitam a intuição; como também o "estar atento" às "sincronicidades" $e$ às coincidências significativas. Por essas coincidências, muitas vezes o profissional de saúde consegue compor um todo que antes se encontrava disperso. E se não há atenção para perceber essas coincidências, elas passam sem que se note qualquer diferença.

Conforme Muniz (1988) assinala, muitas vezes observamos que na situação clínica, comunicações de vários tipos, soltas aparentemente sem significado específico naquele instante, vão se "agrupando" até emergirem subitamente num insight do analista, do paciente ou de ambos.

O terceiro ponto levantado na pesquisa de Tatano Beck refere-se à importância da observação precisa e criteriosa de insinuações ou gestos sutis, $e$ está relacionada à capacidade de perceber pequenas mudanças no comportamento dos pacientes, na maior parte dos casos demonstrados de maneira não-verbal. No artigo de Benner \& Tanner (1987) foi mencionado que a observação da vida cotidiana é um componente necessário para qualquer processo de diagnose. Clínicos experts aprendem a usar o que foi denominado "material tolo - a quê os pacientes se assemelham, como falam, como se alimentam etc., em suas compreensões ordinárias e triviais" -, no reconhecimento de tendências sutis das doenças. Para Muniz (1988), a expressão "olho clínico" é de amplo conhecimento de todos para designar a qualidade sensitiva na capacidade de diagnosticar, que inclui os atributos pessoais além da experiência acumulada.

Concordamos com esses autores e ressaltamos a importância da atenção apurada para se observar os pequenos detalhes, os sinais imperceptíveis, os gestos inconscientes, os toques e os silêncios, pois eles podem traduzir aquilo 
que as palavras muitas vezes não conseguem expressar. Um paradigma de conhecimento que incorporava esse princípio da observação de pequenas sutilezas ou indícios quase imperceptíveis existiu na humanidade mais primitiva e povoou a medicina do final do século XIX, entretanto não vingou diante do modelo biomédico que se tornou hegemônico. Ele nos foi apresentado pelo historiador Carlo Ginzburg (1991) e constituía-se em um paradigma indiciário baseado na semiótica médica; "a disciplina que permite diagnosticar as doenças inacessíveis à observação direta na base de sintomas superficiais, às vezes irrelevantes aos olhos do leigo" (p.151). O que caracteriza esse saber, segundo Ginzburg, é a capacidade de, a partir de dados aparentemente negligenciáveis, remontar a uma realidade complexa não experimentável diretamente. Ele quer nos mostrar que são justamente os pormenores mais negligenciáveis, ou seja, os elementos subtraídos ao controle da consciência ou os pequenos gestos inconscientes, ou ainda os indícios quase imperceptíveis, que nos permitem captar uma realidade mais profunda que, de outra forma, seria inatingível.

Por meio de exemplos retirados de diversos momentos históricos, Ginzburg (1991) aponta para a relevância do saber nascido da experiência, como ele afirma, da concretude da experiência, residindo aí a força desse tipo de saber. São, portanto, formas de saber mudas, no sentido de que suas regras não se prestam a serem formalizadas nem ditas. Nesse tipo de conhecimento entram em jogo elementos imponderáveis, tais como: faro, golpe de vista, olhar-clínico, intuição. Esse tipo de saber indiciário aplica-se bem à medicina, uma vez que esta trabalha qualitativamente com casos individuais, em situações conjeturais específicas, em que cada situação vivida pelo terapeuta e o paciente é única em relação a todas as demais.

Enfim, esses três pontos mencionados acima e levantados a partir da pesquisa coordenada pelo professor Tatano Beck (1998) foram passados para os graduandos de enfermagem que, ao saberem dos resultados, se sentiram aliviados em poder expressar os sentimentos intuitivos que já haviam sentido anteriormente em suas experiências clínicas.

\section{Considerações finais}

No contexto atual da clínica médica observamos uma certa crise do modelo dominante, no qual algumas "verdades" até então inabaláveis estão sendo colocadas em cheque. A prática clínica tem apontado para a não dissociação do corpo e da alma, e os profissionais de saúde já admitem recorrer à intuição em determinados julgamentos clínicos. A questão é isso ser assumido, expandido e aperfeiçoado.

O Método Intuitivo de Bergson mostra-se eficaz uma vez que incorpora tanto o conhecimento racional acumulado pelo saber médico, quanto o imprevisível que permeia a relação terapeuta-paciente. Sua singularidade recai, sobretudo, em uma atitude de despojamento diante das idéias preconcebidas e, portanto, fixas e imutáveis, em função de um deixar-se fluir, junto ao tempo, para que a partir dessa vivência harmônica na duração possam emergir os signos e sinais capazes de dar as chaves para a compreensão do sofrimento do outro. A partir dessa vivência compartilhada, permeada pelo cuidado e por afetos, sensações, idéias e percepções sensíveis, o terapeuta torna-se mais apto 
a intuir, por sua sensibilidade, aquilo que pode estar afligindo seu paciente, ou seja, por meio de sua intuição o terapeuta pode conseguir captar algo do espírito de seu paciente, facilitando o processo de cura.

Procuramos mostrar que a medicina ocidental vem, nos últimos séculos, privilegiando a ciência das doenças, devido a seu grau de determinação $e$ objetividade; e deixando de lado, em contrapartida, a arte de curar, que implica uma certa criatividade, pois exige do terapeuta mais do que apenas assimilação de conhecimento, exige sensibilidade e intuição para lidar com o novo, o contingente e o desconhecido. Habilidades que o terapeuta necessita ter, pois o trabalho médico, como mostrou Lilia Schraiber (1997), é uma estrutura instável, pois lida de forma particular com cada indivíduo e a cada vez em que ele é atendido.

Esta pesquisa também procurou mostrar ser o paradigma técnicocientificista a reger a medicina ocidental contemporânea insuficiente para dar conta da questão da cura. A prática clínica é uma forma de ação que escapa ao modelo da filosofia clássica e aos ditames da ciência moderna, sobretudo a aplicada à medicina, uma vez que reduz a prática médica a intervenções mecânicas e técnicas, centradas na doença e não no indivíduo doente. Não podemos subestimar o valor da técnica e da ciência para a medicina e para o aumento da expectativa de vida das pessoas, não se trata de superá-las. Mas levar em conta somente estes aspectos é não estar atento para a totalidade da vida, não sendo, com isto, fiel à completude do real.

\section{Referências}

BENNER, P.; TANNER, C.Clinical judgment: How expert nurses use intuition. Am. J. Nurs., v.87, n.1, p. 2331, 1987.

BERGSON, H. Introdução à metafísica. São Paulo: Abril Cultural, 1974. (Os Pensadores).

BOFF, L. Saber cuidar: ética do humano, compaixão pela terra. Petrópolis: Vozes, 1999.

BRUGGER, W. Dicionário de filosofia. São Paulo: Pedagógica e Universitária, 1977.

CANGUILHEM, G. O normal e o patológico. Rio de Janeiro: Forense-Universitária, 1978.

ClOFFI, J. Heuritics, servants to intuition, in clinical decision-making. J. Adv. Nurs., v.26, n.1, p.203-8, 1997.

DELEUZE, G. El bergsonismo. Madrid: Cátedra, 1987.

DELEUZE, G. A imagem do pensamento. In: DELEUZE, G. Diferença e repetição. São Paulo: Graal, 1988. p.215-73.

EASEN, P.; WILCOCKSON, J. Intuition and rational decision-making in professional thinking: a false dichotomy? J. Adv. Nurs., v.24, n.4, p.667-73, 1996.

ENGLISH, I. Intuition as a function of expert nurse; a critique of Benner's novice to expert model. J. Adv. Nurs., v.18, n.3, p.387-93, 1993.

GINZBURG, C. Sinais: raízes de um paradigma indiciário. In: GINZBURG, C. Mitos, emblemas, sinais. São Paulo: Cia. das Letras, 1991. p.143-79.

GUIMARÃES, M. B. Intuição e arte de curar: pensamento e ação na clínica médica. Rio de Janeiro: UERJ/IMS, 2000. (Estudos em Saúde Coletiva, 203). 
GUIMARÃES, M. B. L.

GUIMARÃES, M. B. Intuição e arte de curar: pensamento e ação na clínica médica. 2001. Tese (Doutorado) - Instituto de Medicina Social, Universidade do Estado do Rio de Janeiro, Rio de Janeiro.

ILLICH, I. A expropriação da saúde: nêmesis da medicina. Rio de Janeiro: Nova Fronteira, 1975.

KING, L.; APPLETON, J.V. Intuition: a critical review of the research and rhetoric. J. Adv. Nurs., v.26, n.1, p.194-202, 1997.

LALANDE, A. Vocabulário técnico e crítico da filosofia. São Paulo: Martins Fontes, 1993.

LUZ, M. T. Cultura contemporânea e medicinas alternativas: novos paradigmas em saúde no fim do século XX. Physis, v.7, n.1, p.13-43, 1997.

MACIEL JR., A. O todo aberto: tempo e subjetividade em Henri Bergson. 1997. Dissertação (Mestrado) Departamento de Pós-Graduação de Filosofia, Universidade do Estado do Rio de Janeiro, Rio de Janeiro.

MARTINS, A. Novos paradigmas e saúde. Physis, v.9, n.1, p.83-112, 1999.

MEYERS, M. A. Science, Creativity and Serendipity. AJR., n.165, p.755-64, 1995.

MUNIZ, J. R. Intuição: um ensaio teórico. Inform. Psiquiatr., v.7, n.3, p. 99-104, 1988.

O'CONNELL, D. Intuition and the nursing process. J. Contin. Educ. Nurs., v.23, n.5, p.196, 1992.

ORLICK, S.; BENNER, P. The primacy of caring. Am. J. Nurs., v.88, n.3, p.318-9, 1988.

SCHRAIBER, L. B. Medicina tecnológica e prática profissional contemporânea: novos desafios, outros dilemas. 1997. Tese (Livre-docência) - Faculdade de Medicina, Universidade de São Paulo, São Paulo.

SILVA, A. L. Reflexões sobre a experiência de uma enfermeira no cuidar de clientes com AIDS, com base no modelo homeodinâmico. Rev. Gaúcha Enferm., v.14, n.2, p.94-101, 1993.

TATANO BECK, C. Intuition in nursing practice: sharing graduate students' exemplars with undergraduate students. J. Nurs. Educ., v.37, n.4, p.169-172, 1998.

TESSER, C. D. A biomedicina e a crise da atenção à saúde: um ensaio sobre a desmedicalização. 1999. Dissertação (Mestrado) - Faculdade de Ciências Médicas, Universidade Estadual de Campinas, Campinas.

GUIMARÃES, M. B. L. Intuición, pensamiento y acción en la clínica. Interface - Comunic., Saúde, Educ., v.9, n.17, p.317-32, mar/ago 2005.

Este trabajo es un estudio de naturaleza teórico-conceptual, con dos líneas de narrativa: una en el campo de la filosofía y otra en el plano del análisis sociológico del conocimiento o de la cultura; que, en este caso, tuvo lugar en el campo del discurso de la clínica. Este estudio se propone contribuir al análisis de la cuestión de la diagnosis, de la terapéutica y del cuidado en la cultura occidental contemporánea. El objetivo específico fue trabajar con la categoría de la intuición como elemento básico del conocimiento de la práctica clínica, a través del análisis del proceso manifestado en terapeutas y pacientes durante el tratamiento. Hicimos uso del Método Intuitivo propuesto por Henri Bergson, con la intención de delimitar un pensamiento estrictamente racional y proponer la trasposición de este método a la instancia clínica. En este estudio, la intuición fue tratada como una forma sintética de percepción/pensamiento, en la cual la realidad es comprehendida por una consciencia inmediata, regida por la sensibilidad.

PALABRAS CLAVE: intuición; relaciones profesional-paciente; experiencia; juicio clínico. 